\title{
Farm/crop portfolio simulations under variable risk: a case study from Italy
}

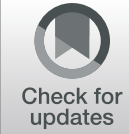

\author{
Franco Rosa, Mario Taverna, Federico Nassivera and Luca Iseppi i
}

\author{
* Correspondence: \\ luca.iseppi@uniud.it \\ Department of Agricultural, Food, \\ Environmental, and Animal \\ Sciences, Section of Economics, \\ University of Udine, Via delle \\ Scienze, 206, 33100 Udine, Italy
}

\begin{abstract}
Important sources of risk in agriculture are yield and price fluctuations caused by unpredictable and uncontrollable events, inducing income volatility and adding considerable complexity to farmers' decisions. The literature suggests that these events could affect farmers' risk aversion in decision making and justify their preferences for risk minimizing and safety-first survival, rather than a profit maximization strategy. The aim of this study is to test this hypothesis by using a quadratic programming in linearized version and the sumex utility function, which is representable as sum of products of polynomials and exponential (or "polynex") functions to simulate risk aversion for specific traits of the E-V frontier (Nakamura, Mathematical Soc Sci 31:39-47, 1996). The linear approximation of the utility function is obtained with the MOTAD approach, consisting in the minimization of errors generated by total absolute deviations of gross income from the expected value (Hardaker et al. Rev Mark Agric Econ 59:9-22, 1991). This method allows different portfolio simulations to be run of selected cereal and oilseed crops as risky prospects, by varying the risk parametrically. The results obtained confirm the hypothesis that risk affects farmers' decisions and that crop diversification is a viable strategy as a hedge against risk.
\end{abstract}

Keywords: Farm planning, Risk assessment, Sumex utility function, LP-MOTAD, Portfolio analysis

JEL: Q12, G11, C61

\section{Introduction}

Hardaker et al. (2007) suggest two main sources of risk substantially affecting farmers' decisions: business and financial risks. Business risks are combinations of various sources, generated by the unpredictable nature of the weather causing the uncertain performance of farmers' incomes. Price risks refer to the price volatility of farm inputs and outputs (Rosa et al. 2014). In a survey conducted in the Netherlands, the price risks were perceived as the most important, while financial risks were ranked least relevant (Meuwissen et al. 2001). The lesson is that farmers should be better informed about the risk sources and react by combining their farm enterprises more efficiently. This topic has been explored by many researchers in farm management problems. Farmers usually elaborate their production plan in a context of limited information that biases the outcomes of their decisions, even in a shorter time horizon (Bernstein, 1996; Chen et al. 1999; OECD 2000; Shapiro et al., 1993; Stewart 1991). ${ }^{1}$ These

(c) The Author(s). 2019 Open Access This article is distributed under the terms of the Creative Commons Attribution 4.0 International License (http://creativecommons.org/licenses/by/4.0/), which permits unrestricted use, distribution, and reproduction in any medium, provided you give appropriate credit to the original author(s) and the source, provide a link to the Creative Commons license, and indicate if changes were made. 
decisions affect crop supply and incomes in the short term, while the rigidity of the assets invested in longer periods and higher fixed costs increase the difficulty in adjusting the farmers' decisions about risky crop prospects (Anderson et al. 1977, Anderson and Hardaker 2003, Anderson et al. 2004; Hardaker et al. 2007; Markowitz 1952). Price volatility is an external source of risk, whose importance is growing due to changes in the farming environment and strengthening of the integration between agricultural and commodity markets (Rosa et al. 2014). One example is the high price volatility of the oil markets due to financial speculation, transmitted to the agricultural input markets through prices of fertilizer, feedstock, pesticides, machinery, etc. Table 1 summarizes some sources of risk affecting farmers' decisions.

The farm situation in Italy is represented by 1.5 million units with average UAS of 10 ha; smaller farmers are the majority of the rural population, and in most cases, they are unable to deal with the complexity of the agricultural sector (Salvioni et al. 2009; Dries et al. 2012). Limits in entrepreneurial skills could be a factor that influences the risk avoider attitude. ${ }^{2}$ Due to fear of losing all their assets in the case of adverse events, risk aversion could address preferences towards "risk minimization and safety-first" instead of a profit maximizing strategy (Kaine et al. 1994; Oguntade and Bamire 1994; Anderson et al. 1977; Knight 1971; Matlon 1991; Chavas and Holt, 1990; Martin and Shadbolt 2000; Anderson and Hardaker 2003, Anderson et al. 2004; Manfredo and Leuthold 1999; Sulewski and Kłoczko-Gajewska 2014). ${ }^{3}$ In a survey to test farmers' preferences for risk in the Netherlands, Meuwissen et al. (2001) found that risk aversion was correlated to changes in crop yield and suggested that "higher expected level of farmers' incomes in certain conditions do not balance the risk of losing their assets ${ }^{4}$." Tobin (1965) says that under risky conditions (variance), averse decision makers formulate their optimal portfolio with crop diversification (risky prospects), while for risk preferring decision makers, the optimal portfolio will be reduced to few or a single risky prospect. Crop diversification in farm planning is then usually adopted to hedge against risk; as the average of the sum of variance and covariance of different price-yield combinations compensate for each other if the risk factors are similar and are generally

Table 1 Risk sources in the agricultural sector

\begin{tabular}{|c|c|c|c|}
\hline $\begin{array}{l}\text { Nature of } \\
\text { risk }\end{array}$ & $\begin{array}{l}\text { Micro: (idiosyncratic) risk } \\
\text { affecting individual or } \\
\text { household decisions }\end{array}$ & $\begin{array}{l}\text { Meso: (covariant) risk affecting } \\
\text { groups of households or } \\
\text { communities }\end{array}$ & $\begin{array}{l}\text { Macro: (systemic) risk affecting } \\
\text { the entire farm population }\end{array}$ \\
\hline $\begin{array}{l}\text { Market/ } \\
\text { prices }\end{array}$ & $\begin{array}{l}\text { Crop volatility caused by } \\
\text { supply/demand/stock } \\
\text { changes amplified by } \\
\text { inefficient market } \\
\text { conditions }\end{array}$ & $\begin{array}{l}\text { Changes in prices of land, } \\
\text { working capital or food } \\
\text { industry requirements }\end{array}$ & $\begin{array}{l}\text { Changes in input/output prices } \\
\text { due to trade policy, new markets, } \\
\text { or endogenous variability }\end{array}$ \\
\hline Production & $\begin{array}{l}\text { Climate, pests and } \\
\text { diseases, personal } \\
\text { hazards, wrong } \\
\text { technology }\end{array}$ & $\begin{array}{l}\text { Climate change, rainfall, } \\
\text { land-slides, environmental } \\
\text { pollution }\end{array}$ & $\begin{array}{l}\text { Changes in market conditions: } \\
\text { input/output prices }\end{array}$ \\
\hline Financial & $\begin{array}{l}\text { Changes in level of } \\
\text { incomes from off-farm } \\
\text { jobs; lack of private } \\
\text { sources for investments }\end{array}$ & $\begin{array}{l}\text { Bankruptcy, asset risk, cross- } \\
\text { market interactions, market } \\
\text { efficiency }\end{array}$ & $\begin{array}{l}\text { Changes in interest rate, affecting } \\
\text { capital and financial assets, market } \\
\text { volatility induced by off-farm } \\
\text { events, future market volatility and } \\
\text { spot markets }\end{array}$ \\
\hline $\begin{array}{l}\text { Institutional/ } \\
\text { legal }\end{array}$ & Liability risk & $\begin{array}{l}\text { Changes in local agricultural } \\
\text { and food policy }\end{array}$ & $\begin{array}{l}\text { Changes in regional/national/EU } \\
\text { policy and interventions on } \\
\text { production/marketing }\end{array}$ \\
\hline
\end{tabular}


inferior to the variance of a single crop (Mishra et al. 2004; Backus et al. 1977). ${ }^{5}$ The optimal combination of risky prospects about crops generates the efficient $\mathrm{E}-\mathrm{V}$ frontier (Fig. 1), representing the locus of efficient solution with maximum $E$ value for a given variance (or $\mathrm{s} . \mathrm{d}=\mathrm{V}^{0.5}$ ) or minimum variance for a given $\mathrm{E}$ value. The literature reports different methods to assess farmers' risk attitudes with computable models of the E-V frontier (Hardaker et al. 1988; Anderson and Hardaker 2003; Backus et al. 1997). The approach proposed in this research is based on (i) the variance of total gross income (GI) in the crop combination portfolio, using quadratic risk programming in the linear version to approximate the quadratic E-V frontier and (ii) introduction in the subjective expected utility (SEU) of individual beliefs and preferences about risk (Pannell and Nordblom 1988; Backus et al. 1997; Bazerman 2006). The subjective probabilities about changes in frequency of risky prospects are justified by the different farmers' knowledge about external events (climate, market, finance, policy, etc.) that affect the SEU of farmers' beliefs about future events (Hardaker et al. 1991, 2007; Pannell and Nordblom 1988). With these premises, the objective is to simulate optimal crop combinations portfolio of risky prospects about crops with an "ad hoc" utility function to parameterize the risk for specific traits of it. ${ }^{6}$ The solutions are used to draw the E-V frontier and the tangency between utility and E-V frontier will give the optimal solution for portfolio crop combination. The risk is assessed with the mean and variance moments of some diffuse crops in Italy. Four cereal crops: maize, barley, wheat, sorghum, and three oilseed crops: soybean, rapeseed, and sunflower, are selected for the crop portfolio solution. ${ }^{7}$ The stochastic condition is assessed by using the yield and price fluctuations of these crops, assuming that the annual observations are drawn from a stochastic distribution of events (Markowitz 1952; Stovall, 1966; Taylor 1990; Lien and Hardaker 2001; Pope 1982; Hardaker et al. 1988). ${ }^{8}$ A second observation concerns linear segmentation of the utility function, which is a quadratic approximation to facilitate application of the parametric linear programming method, without losing the stochastic nature of the activity (Hardaker et al. 1988). The problem is formulated as the minimization of risk to a range of possible levels of expected $\mathrm{GI}^{9}$ subject to farm constraints and other restrictions (Hazell and Scandizzo 1974; Anderson et al. 1977, p 207).

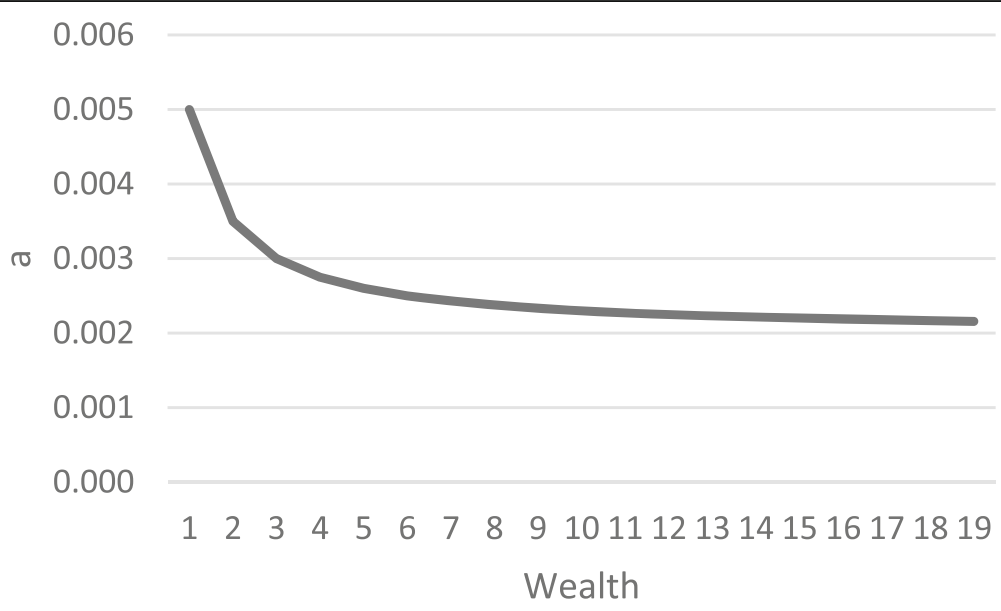

Fig. 1 Efficient E-V frontier for whole farm planning 
This research is organized as follows: the "The utility efficient programming and linearization with MOTAD" section is a discussion on the properties of the sumex utility function (SUF) (Fig. 2) and risk modulation for its specific traits, the parametric programming method, and linearization; the "Empirical analysis: the risky prospects " section discusses the sample of risky prospects used for empirical analysis; the "Computation of utility efficient frontier " section is dedicated to analysis of the utility efficient frontier; the "Conclusions" section analyzes the results obtained with evidence of the initial hypothesis about crop diversification and other suggestions to implement these results.

\section{The utility efficient programming and linearization with MOTAD}

In this section, we examine the stochastic production frontier obtained with the efficient programming method (Hanoch and Levy 1970; Hardaker et al. 1991; Ghodake and Hardaker 1981; Meyer 1977; Lee et al. 1985; Kaiser and Apland 1989; Hossain et al. 2002; Lien and Hardaker 2001; Park et al. 2004). The efficient set of portfolio solutions is obtained with a formulation of appropriate objective function to modulate risk, and the MOTAD method is used to linearize the function to obtain an efficient set of portfolio plans.

The sumex utility function (SUF) proposed by Patten modulates the risk with $\lambda$

$$
\mathrm{U}(z)=\mathrm{G}(z)+\lambda(\mathrm{H}(z))
$$

where $Z$ is the wealth variable in the $G$ and $H$ polynomials of the sumex function that satisfies the desired properties of separability and concavity conditions obtained with first and second derivatives, while the risk aversion is simulated by varying $\lambda$ parametrically in the range between a and b (Hardaker et al. 1988; Nakamura 1996). The SUF with first- and second-order derivatives is reported below:

$$
\begin{array}{lr}
\mathrm{U}(z)=-\exp (-\mathrm{a} z)-\lambda^{*} \exp (-\mathrm{b} z) \quad \text { with } \lambda, \mathrm{a}, \mathrm{b} \geq 0 & \text { SUF function } \\
\mathrm{U}^{\prime}(z)=-\mathrm{a} \exp (-\mathrm{a} z)+\lambda \mathrm{b} \exp (-\mathrm{b} z)>0 & \text { 1st derivative } \\
\mathrm{U}^{\prime \prime}(z)=-\mathrm{a}^{2} \exp (-\mathrm{a} z)-\lambda \mathrm{b}^{2} \exp (-\mathrm{b} z)<0 & \text { 2nd derivative }
\end{array}
$$

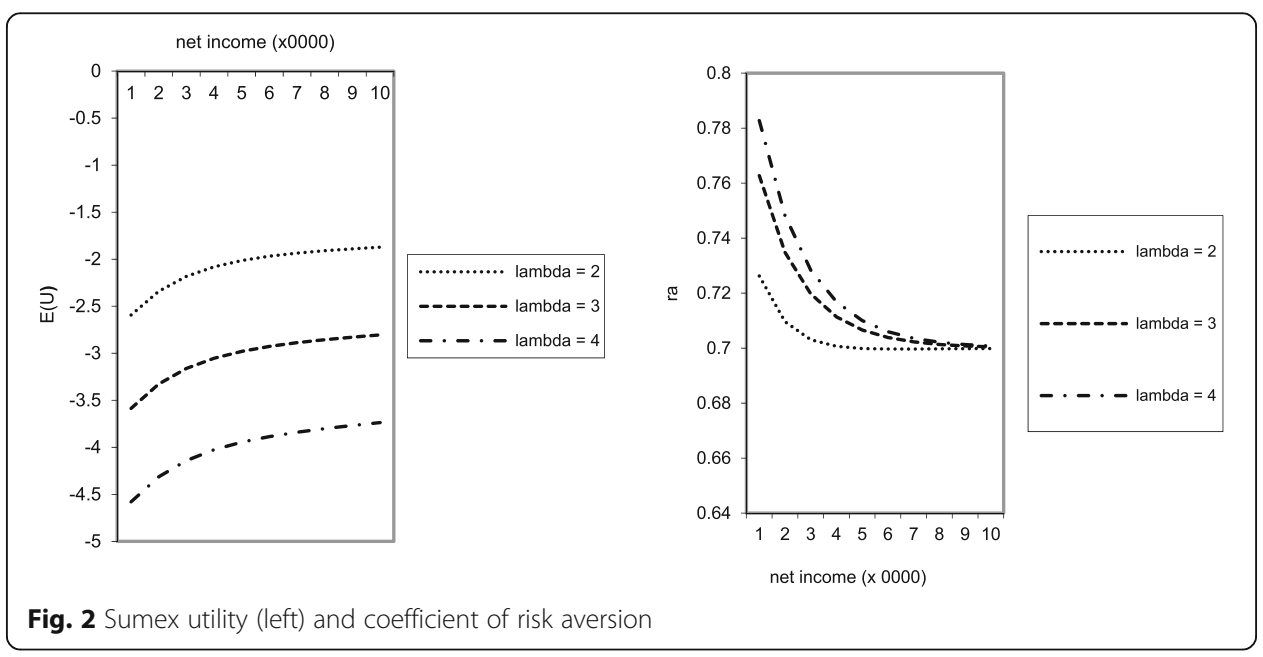


The SUF implies decreasing risk aversion as $z$ increases, assuming "normal behaviour." The coefficient of absolute risk aversion $\lambda$ ranges between the extreme limits a and $\mathrm{b}$, with the following parametric restrictions on $\mathrm{a}$ and $\mathrm{b}$ : $\mathrm{a}$ (minimum risk) for $\lambda=$ 0; b (maximum risk) for $\lambda=\max$. The linear segmentation of SUF allows to find efficient solutions using a parametric linear programming method for the efficient farm plan. Since $\mathrm{G}(z)$ and $\mathrm{H}(z)$ satisfy the concavity condition, the Duloy and Norton procedure can be used to find the linear approximation (McCarl and Önal 1989). The efficient programming is based on the linearized quadratic risk programming (QRP) method that uses a matrix of crop GI deviations from the mean value. The E-V combinations are the set of efficient solutions obtained with the minimization of variance subjected to the parametric constraint of expected income (GI). Hence, the MOTAD linear approximation of the QRP and E-M combinations obtained with MOTAD are an acceptable proxy for the E-V combinations obtained from quadratic function (McCarl and Önal 1989; Lambert and McCarl 1986). The method proposed by Hardaker et al. (1988) is based on a separable utility function in an efficient programming model:

$$
\operatorname{Max} E(U)=\sum \rho_{k}\left(G(z)+\lambda \rho_{k} H(z)\right) \text { with } \lambda \text { varied parametrically }
$$

subject to $\overline{\mathrm{R}}^{\prime} \mathrm{x}=e$ and $\mathrm{Ax} \leq \mathrm{b}$; for all $\mathrm{x} \geq 0$

where $\mathrm{E}(\mathrm{U})$ is the sumex utility function; $\mathrm{G}$ and $\mathrm{H}$ are the two polynomial risk components of the SUF, $\mathrm{p}_{\mathrm{k}}$ is the probability of state $k$ and $\lambda$ is a non-negative parameter varied parametrically between 0 and maximum value in a defined interval of the risk aversion; $\mathrm{R}=\mathrm{E}(\mathrm{GI})$ is an unbiased estimator of $\mathrm{GI}$ and $\mathrm{R}^{\prime} \mathrm{x}$ is the estimated vector of expected GI generated from the activities $\mathrm{x}$ included in the crop portfolio; and $\mathrm{x}$ is the vector of activity level (positive values), $e$ is the maximum acceptable limit of risk by farmers, and A is the matrix of technical coefficients of resources used in activity $\mathrm{x}$, constrained to resource limit b (Hardaker et al. 1988; Pope 1982).

The relation between utility function and the efficient frontier has a solid empirical basis when there is exhaustive knowledge of the production coefficients. In this case, the objective function will capture the utility dimension embedded in the expected GI function (Hardaker et al. 2007; Ignizio 1982; McCarl and Önal 1989). A relevant question concerns the optimal size of the sample GI to reduce bias (Pope 1982). Many authors have suggested that the normal distribution of states is not required, as any observation about a risky prospect can be assumed to be a representative random event of equally likely outcomes or states with subjectively assessed probabilities. Table 1 reports the moments generating risk, mean, SD, and CV referring to the yield and prices of the sample of crops representing the risky prospects of the commodities used in the analysis. The standard deviation values of yields (s.d.) fluctuate in the range between 0.18 for sunflower and 0.59 for maize; these values are much lower than the s.d. of prices that fluctuate in the range between 1.84 for barley and 10.22 for rapeseed. The covariance values show the risk generated by the combination of price and yield changes affecting the farmers' GI; the lowest absolute value is for barley $(-0.01)$, the highest for soybean $(-0.71)$. The price variability compared to yield variability ranges from moderately high (less than 10 fold for rapeseed, sorghum, maize, and wheat) to very high (for barley, soybean, and sunflower). 
The sample mean activity GI includes 14-year observations (1995-2008) about the states of nature assumed to have equal probability;

$$
\mathrm{p}_{\mathrm{r}}, \text { for } \mathrm{r}=1 . .14 \text { with } \sum_{r=1}^{14} \operatorname{Pr}=1 \text { and } \mathrm{p} 1=\mathrm{p} 2=\ldots \mathrm{p} 14=1 / 14=0.07=7 \%
$$

The optimal portfolio combination of farm crops is computed using the stochastic utility efficiency frontier (UEF) and solved with the linear programming MOTAD procedure to minimize the total absolute deviations (MOTAD) of GI from mean value instead of using the variance as a measure of risk for the estimation of (E, V) efficient production frontiers. This method, first proposed by Hazell (1971) as a linear alternative approach to quadratic programming, has achieved substantial popularity due to its efficiency (Hazell and Scandizzo 1974). Computationally, the method has the important advantage of offering solutions to the problem by using a conventional linear programming approach. Also, in spite of the additional constraints and variables required, the formulation is highly tractable with respect to computing requirements. The MOTAD applies ordinary linear programming to simulate the farmers' planning decisions (Brink and McCarl 1978). MOTAD in target version has the important advantage that solutions are second degree stochastically dominant, meaning that they are stochastically efficient for risk-averse decision makers (Hardaker et al. 1991). With this method, it is possible to obtain reliable results in situations where farmers' decisions become increasingly complicated due to the instability of prices and yields affecting the crop combinations. The solution proposed by Hazell consists of risk computation using the LP-MOTAD approach to minimize the minimum absolute deviation (MAD) for a given level of expected GI. The assumptions of utility efficient programming are the linearity condition, and ahj, bhj, and $c^{* j}$ to be known and constant. The objective function is the SUF with $\lambda$ varied parametrically between 0 and a very high value and $\mathrm{pk}=1 / 14=0.07=7 \%$.

$\mathrm{E}(\mathrm{U})$ is the expected value of SUF, $K=1 . .14$ indicates the equally probable state of nature of all crops. $\mathrm{E}(\mathrm{U})$ is non-linear, then a procedure to approximate the SUF has been used (McCarl and Önal 1989). zk is the expected gross income deviation given by (crjcj) to be maximized with a parametric constraint on the sum of negative deviations.

$$
\begin{aligned}
& \sum_{j=1}^{7}\left(a_{h j}{ }^{*} x_{j} \leq b_{h}\right) \text { for } h=1 . . n \\
& \sum_{j=1}^{7}\left(c_{r j}-\bar{c}_{j}\right) x_{j}+y_{r} \geq 0 \text { for } r=1 . . s \\
& \sum_{r=1}^{14}\left(y_{r} \leq \lambda\right) \text { for } a=0 \leq \lambda \leq b
\end{aligned}
$$

The assumption for the validity of this computation is that all the risky prospects about crops, crj for $j=1 . .7$ the crop indicator and $r=1 . .14$ the year indicators are equally probable and all the crj are random extractions from a distribution of random natural events (Pope 1982).

All $x$ and $y$ are non-negative variables, and $\lambda$ is varied parametrically from 0 to a very high value to determine the change in crop composition to a change in risk level. 


\section{Constraint description:}

Constraint 8 specifies the restrictions of land, labor, and working capital resources $\mathrm{bh}$; for $\mathrm{h}=1 . . \mathrm{m}$.

Constraint 9 is specific to MOTAD and imposes the non-negative condition that all deviations of a specific crop crj-c ${ }^{* j}$ for all activities $j(j=1 . .7)$ and year $r(r=1 . .14)$ multiplied by their use $\mathrm{x}$ in the crop activity. The variable $Y \mathrm{r}$ measures the negative deviations of GI for all states of nature $r=1$..s. If the sum of total deviation for each state is positive, $Y \mathrm{r}$ is equal to 0 .

Constraint 10 accounts for the sum of total negative deviations for the 14 states crj$\mathrm{C}^{*} \mathrm{j}$ for $r(r=1 . .14)$ inferior to $\lambda$ value. It is responsible for the basis change of specific critical lambda values.

\section{Empirical analysis: the risky prospects}

Data about gross farm income (GI) per hectare are collected for a period of 14 years (source Eurostat) for the following crops: wheat, maize, barley, sorghum, rapeseed, soybean, and sunflower. ${ }^{10}$ Every year represents a state of nature, and it is assumed that each one is randomly extracted from a set of events with the same probability of occurring. ${ }^{11}$ It is also assumed that the decisions to sow these crops are not constrained by the need to produce a minimum quantity to feed livestock or a rotation that would require additional constraints.

Table 2 reports the crop vectors of GI, which is the information disclosed to farmers about risky crop prospects and is used for their planning decisions. ${ }^{12}$ It is a multivariate normal distribution, generated by yield and price variations that are stochastically independent as shown by the unconditional or marginal distribution of the two discrete random variables ${ }^{13}$ (Anderson et al. 1977). The risk is generated by the yearly changes of GI measured with the following: mean, standard deviation, and coefficient of variation. ${ }^{14}$ A wider range of $\mathrm{CV}$ fluctuation is observed for rapeseed (0.41) and barley (0.51); for the other crops, values range between the minimum 0.12 (sunflower) to the maximum 0.22 (wheat).

For the activity sample reported in Table 2, the unbiased estimates of the mean absolute deviations of expected GI are calculated with the following formula:

$$
\text { M.. }=s^{-1} \sum_{r=1}^{s}\left|\sum_{j=1}^{n}(c r j-\overline{c j}) x j\right|
$$

where $s$ is the sample size composed of seven vectors (crops), each of which includes 14 observations, for a total of 98 observations about GI;

$\mathrm{Cr}_{\mathrm{j}}$ is a single observation of the GI sample, referred to the $j$ th activity and $r$ th year;

$\overline{c j}$ is the sample mean of GI referred to the $j$ th activity, the mean, and standard deviation are the moments calculated on discrete values of the risky prospects, and PDF are the values to test for the normality distribution of the risky prospects.

The values reported in Table 2 are used to compute the mean absolute deviation values reported in Table 3.

The MOTAD method requires a measure of the minimum absolute deviation of GI from its mean value; these values are reported in Table 3. 
Table 2 Crop vectors of $\mathrm{Gl}(€ / \mathrm{Ha})$ representing the risky prospects of seven crops for 14 years of observation

\begin{tabular}{llllllll}
\hline Year & Wheat $(r=1)$ & Maize $(r=2)$ & Barley $(r=3)$ & $\begin{array}{l}\text { Sorghum } \\
(r=4)\end{array}$ & $\begin{array}{l}\text { Rapeseed } \\
(r=5)\end{array}$ & $\begin{array}{l}\text { Soybean } \\
(r=6)\end{array}$ & $\begin{array}{l}\text { Sunflower } \\
(r=7)\end{array}$ \\
\hline 1 & 577.87 & 1698.23 & 649.35 & 699.35 & 320.41 & 693.14 & 441.52 \\
2 & 603.05 & 1586.58 & 621.38 & 644.59 & 228.16 & 766.48 & 396.66 \\
3 & 439.59 & 1323.76 & 507.29 & 629.58 & 147.76 & 884.80 & 395.85 \\
4 & 513.98 & 1326.04 & 530.84 & 525.51 & 164.34 & 694.05 & 390.08 \\
5 & 460.67 & 1451.08 & 529.86 & 602.06 & 159.03 & 580.00 & 359.99 \\
6 & 475.69 & 1340.38 & 548.03 & 611.32 & 181.51 & 657.77 & 374.04 \\
7 & 437.00 & 1312.91 & 492.05 & 633.22 & 183.88 & 723.57 & 373.19 \\
8 & 450.00 & 1341.13 & 482.30 & 632.53 & 254.18 & 831.05 & 457.72 \\
9 & 396.94 & 1094.52 & 459.80 & 508.31 & 254.79 & 599.99 & 333.75 \\
10 & 534.69 & 1489.25 & 554.63 & 641.23 & 317.20 & 712.04 & 481.71 \\
11 & 431.49 & 1185.70 & 482.00 & 468.10 & 270.14 & 639.05 & 451.14 \\
12 & 491.16 & 1207.15 & 522.18 & 481.64 & 262.80 & 528.37 & 415.78 \\
13 & 600.00 & 1713.41 & 629.53 & 658.21 & 384.54 & 667.46 & 482.00 \\
14 & 650.00 & 1833.22 & 695.83 & 884.44 & 544.81 & 910.73 & 501.17 \\
Mean state & 504.44 & 1421.67 & 550.36 & 615.72 & 262.40 & 706.32 & 418.18 \\
$r=\left(\bar{c}_{j}\right)$ & & & & & & & \\
St. dev. & 111.73 & 217.68 & 279.52 & 104.85 & 106.90 & 111.21 & 51.47 \\
CV PDF* & 0.220 .00242 & 0.150 .00138 & 0.510 .00141 & 0.170 .00263 & 0.410 .00234 & 0.160 .00326 & 0.120 .00529 \\
\hline Source & & & & & & &
\end{tabular}

Source-our elaboration from Eurostat data

\section{Computation of utility efficient frontier}

The points on the efficient frontier correspond to the corner solutions; at this point, the efficient combination of risky crop prospects (efficient portfolio solutions) with the optimal GI values constrained by the level of risk aversion is obtained with the parametric change of $\lambda$ (Hardaker et al. 2007; Ray et al. 1998; Hazell and Scandizzo 1974; Richardson et al. 2000). Starting with the initial value $\lambda=0$ equivalent to a, the value of $\lambda$ is progressively augmented to find the next corner solution; at this point, the value is the optimal combination of risky crop prospects compatible with the level of GI risk chosen. The simulation continues by changing $\lambda$ parametrically to find the next corner solution and continuing to reach the superior limit b. After an exhaustive number of corner point solutions is found, it is possible to draw a figure that indicates the optimal crop portfolio combinations for a given level of risk. Table 3 reports ten corner point solutions that signal the optimal values of the objective function $\mathrm{U}(z)$, for $\lambda$ varied in the range between 1480 and 12,000. These solutions suggest the crop portfolio combinations according to farmers' preference for risk. Minimum and maximum values of $\mathrm{U}(z)$ are reported in the first and last line of Table 4; the risk aversion is given by $\lambda / \mathrm{U}$ that is a weighted measure of the relative risk aversion $\lambda$. The results confirm the Tobin hypothesis of increasing crop diversification in portfolio as the risk perception increases. Solution seven gives one of the highest values of weighted risk $\lambda / U=2.53$ corresponding to the highest GI values (1539.64) obtained with the inclusion of seven crops in the portfolio and land use of $98 \%$. Half of the land is cultivated with maize and wheat. The rest is equally divided among sorghum, rapeseed, soybean, sunflower, and lastly barley on $8 \%$. The last line reports the solution corresponding to the highest risk 
Table 3 Mean absolute deviations of a single observation $\mathrm{cr}_{\mathrm{j}}$ from mean state $r$ : $\mathrm{cr}_{\mathrm{j}}-\overline{\mathrm{c}}_{\mathrm{j}}$ (see Table 4)

\begin{tabular}{llllllll}
\hline State & \multicolumn{7}{l}{ Mean absolute deviation of $\mathrm{cr}_{j}$ from the mean state $r\left(\mathrm{Crj}-\bar{c}_{\mathrm{j}}\right)$} \\
\hline & Wheat & Maize & Barley & Sorghum & Rapeseed & Soybean & Sunflower \\
\hline 1 & 73.43 & 276.57 & 98.99 & 83.63 & 58.01 & 13.18 & 23.33 \\
2 & 98.61 & 164.91 & 71.02 & 28.87 & 34.24 & 60.16 & 21.52 \\
3 & 64.85 & 97.91 & 43.07 & 13.86 & 114.63 & 178.48 & 22.34 \\
4 & 9.54 & 95.63 & 19.52 & 90.21 & 98.06 & 12.27 & 28.10 \\
5 & 43.77 & 29.41 & 20.51 & 13.66 & 103.37 & 126.33 & 58.20 \\
6 & 28.75 & 81.29 & 2.34 & 4.40 & 80.89 & 48.55 & 44.14 \\
7 & 67.43 & 108.76 & 58.31 & 17.50 & 78.52 & 17.25 & 44.99 \\
8 & 54.44 & 80.54 & 68.06 & 16.81 & 8.21 & 124.73 & 39.54 \\
9 & 107.50 & 327.15 & 90.56 & 107.41 & 7.61 & 106.33 & 84.44 \\
10 & 30.25 & 67.58 & 4.27 & 25.51 & 54.80 & 5.72 & 63.52 \\
11 & 72.94 & 235.97 & 68.37 & 147.62 & 7.75 & 67.27 & 32.96 \\
12 & 13.28 & 214.51 & 28.18 & 134.08 & 0.40 & 177.95 & 2.41 \\
13 & 95.56 & 291.75 & 79.17 & 42.48 & 122.14 & 38.86 & 63.81 \\
14 & 145.56 & 411.55 & 145.46 & 268.71 & 282.42 & 204.41 & 82.98 \\
Mean r & 64.71 & 177.39 & 56.99 & 71.05 & 75.07 & 84.39 & 43.74 \\
\hline
\end{tabular}

Source-risky prospects for the seven crops. Our elaboration from Eurostat data

with respect to $\mathrm{U}$ with value 2.86 . This is the solution of a risk taker who has adopted the most specialized plan represented by maize covering $85 \%$ of the available land, with no other crops included in the portfolio. The utility is at its maximum absolute value with the maximum absolute risk aversion with $\lambda=120,000$, the ratio $\lambda / \mathrm{U}$ is equal to 2.86 (the slope of the utility frontier shows maximum risk aversion) (Anderson et al. 1977). The minimum value of the $\mathrm{U}(z)$ and minimum risk coefficient $\lambda=1480.47$ are reported on line 1 with land use limited to $62 \%$; the farm plan includes three crops: maize is the most representative covering $40 \%$ of the available land, followed by rapeseed (10\%) and barley (2\%). With risk coefficients $\lambda / \mathrm{U}$ in the range between 2.31 and 2.34, there are three similar solutions for crop distribution with wheat and maize covering $60 \%$ of the land available; the difference is in land use that increases with a

Table 4 Corner solutions and crop diversification

\begin{tabular}{|c|c|c|c|c|c|c|c|c|c|c|c|}
\hline \multicolumn{3}{|c|}{ Utility frontier with risk $(€)$} & \multicolumn{8}{|c|}{ Level of the crops included in in the whole farm plan (\%) } & \multirow[b]{2}{*}{ Diversit } \\
\hline$\lambda$ & $\mathrm{U}(\mathrm{Z})$ & $\lambda / U$ & $\begin{array}{l}\frac{\pi}{\mathbb{D}} \\
\stackrel{0}{5}\end{array}$ & $\stackrel{\stackrel{N}{N}}{\stackrel{N}{\Sigma}}$ & $\begin{array}{l}\frac{\widehat{d}}{\frac{\pi}{\pi}} \\
\infty\end{array}$ & $\begin{array}{l}\frac{\xi}{5} \\
\text { 힌 } \\
\text { के }\end{array}$ & 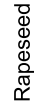 & 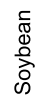 & 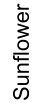 & 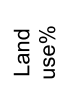 & \\
\hline 1480,47 & 626,11 & 2,36 & 20 & 20 & 0 & 0 & 2 & 20 & 0 & 62 & 4 \\
\hline 1690,62 & 687,45 & 2,46 & 0 & 40 & 2 & 0 & 10 & 0 & 0 & 52 & 3 \\
\hline 1797,42 & 724,49 & 2,48 & 20 & 20 & 2 & 0 & 10 & 20 & 0 & 72 & 5 \\
\hline 2401,43 & 993,83 & 2,42 & 0 & 60 & 2 & 0 & 10 & 0 & 0 & 72 & 3 \\
\hline 3092,66 & 1336,80 & 2,31 & 20 & 40 & 0 & 0 & 0 & 4 & 0 & 64 & 3 \\
\hline 3176,48 & 1358,65 & 2,34 & 20 & 40 & 0 & 0 & 2 & 4 & 0 & 66 & 4 \\
\hline 3685,21 & 1458,01 & 2,53 & 20 & 30 & 8 & 10 & 10 & 10 & 10 & 98 & 7 \\
\hline 3799,31 & 1624,87 & 2,34 & 20 & 40 & 20 & 0 & 0 & 0 & 0 & 80 & 3 \\
\hline 4430,48 & 1883,68 & 2,35 & 20 & 40 & 20 & 0 & 2 & 10 & 7 & 99 & 6 \\
\hline 12000,00 & 4200,00 & 2,86 & 0 & 85 & 0 & 0 & 0 & 0 & 0 & 85 & 1 \\
\hline
\end{tabular}


risk-taking farmer, but these solutions are not favorable economically. The coefficient of risk aversion $\lambda / \mathrm{U}=2.35$ causes the highest crop diversification and a greater land use that is $99 \%$ of the total. This is the best portfolio solution in terms of land use and crop diversification: with wheat, maize, and barley covering 20,40, and 20\%, respectively; soybean $10 \%$; and sunflower $7 \%$. The group of solutions with risk $\lambda / \mathrm{U}$ between 2.36 and 2.42 shows similar results in crop diversification and distribution. The economic results suggest that the risk induces farmers to diversify their crop portfolio and land use when risk aversion increases; in this case, land use also increases consistently.

The plan reported on line 7 is the best one because it includes all crops (maximum diversification), the most land use (98\%), the highest economic value of GI, and a moderate risk aversion.

The hypothesis that farmers' decisions can be affected by the level of risk causing the diversification of the crop portfolio is tested with a linear regression where the dependent variable is the level of $\mathrm{U}(z)$ and the three independent variables are risk level $\lambda$, land use, and crop diversification. The $\mathrm{U}(z)$ is regressed with three independent variables: lambda, land use and crop diversification in single regression: $\mathrm{U}(z)=\mathrm{aX}_{i}$ for $i=$ 1..3. The regression results are reported in Table 5.

Comments: The size of $\lambda$ coefficient means that a $1 \%$ increase in $\lambda$ will cause an increase of $0.37 \%$ in the utility function. The R2 is 0.99 , meaning that the correlation between the two variables is very tight and the high $t$ statistic value suggests the likelihood that the coefficient of $\lambda$ is significantly different from zero.

The crop diversification coefficient suggests a very high direct response of utility change to crop diversification. However, the low values of R2 and $t$ statistic suggest that the diversification effect on the utility value is not so strong. The land use coefficient means that $1 \%$ change in land use will cause a $20.3 \%$ change in utility. The other statistical values are satisfactory, suggesting that the regression results can be accepted as statistically significant.

The regression between $\lambda$ and crop diversification is also statistically significant, suggesting that the increase of risk will induce farmers to diversify the crop portfolio. This result is the answer to the initial hypothesis that the response to increasing risk perception by farmers is the crop diversification decision.

\section{Conclusion}

Risk is an important factor to be considered in farm decisions. The risk aversion is one of the main research questions in farm management, and evaluation of the consequences of risk aversion on farm decision making is crucial to improve the economic results and also has social and political implications. Although risk management

Table 5 Regression results

\begin{tabular}{llll}
\hline $\begin{array}{l}\text { Statistic } \\
\text { values }\end{array}$ & \multicolumn{2}{l}{ Indep variable coeff. values } & \\
\cline { 2 - 4 } Coeff & $\lambda$ & Crop div & Land use \\
SS & 0.375 & 286.025 & 20.375 \\
R2 & 0.011 & 103.688 & 3.833 \\
Df & 0.992 & 0.458 & 0.758 \\
$t$ stat & 9.000 & 9.000 & 9.000 \\
\hline
\end{tabular}


strategies in agriculture are of interest to many authors, the problem of risk aversion and risk management strategies have usually not been analyzed jointly (Meuwissen et al. 2001). In this study, we have tried to implement the farm management decisions by testing the risk aversion in planning caused by fluctuations in yield and prices affecting the wealth measured by GI. Understanding the relationship between farmers' risk attitude and choice of management strategies is important for two reasons. Firstly, the literature suggests that most farmers are averse to risk when faced with risky outcomes. Someone who is risk averse is willing to accept a lower average return for less uncertainty, with the trade-off depending on the individual level of risk aversion. This means that strategies cannot be evaluated solely in terms of average or expected return, but the risk must be accounted in decisions. Secondly, the knowledge of small-scale farmers' attitudes to risk and its management is important in determining the type of strategies. Operationally, this problem has been tackled by using a sumex utility function allowing the risk for specific traits of the function to be modeled and solved with a utility efficient programming in linearized version. A sample of observations about GI for a period of 14 years and seven crops has been collected in Italy (Eurostat source). The same probability distribution of risky prospects generated by fluctuations in yield and prices is assumed. The MOTAD linear approximation method of a quadratic function is used to simulate the crop portfolios at different risk aversion levels. Our results are coherent with those obtained by other authors and suggest that the optimal portfolio solutions depend on both risky prospects generated by a mix of market (price fluctuation) and production (yield variation), with the higher risk generated by the market. The risk generated by price fluctuations in the last years seems to be more important and negatively affects farmers' behavior, causing higher risk aversion than climate variability whose consequences are better controlled by technologies. In fact, commodity prices tend to fluctuate in a range amplified by speculative activities performed in future and financial markets. In the EU, the relative security assured in the past to farmers with the first pillar policies and now enforced with second pillar provisions may have limited the negative impact of risky prospects. Emergency measures are also blamed for undermining existing risk management systems to the extent that farmers are relying on ad hoc government intervention in the case of a crisis rather than risk management with portfolio diversification strategies. Reduced prices support and other protection mechanisms are progressively being replaced by new financial instruments to spread the risk with farm insurance subsidies and market regulation to help farmers to cope with risk sources. A last notation is for non-use of land that occurred in some solutions. This could be interpreted in terms of opportunity cost for pluriactivity that incorporates crop diversification, part-time farming, use of labor in an on- and off-farm mix, and saving land and capital resources. When the risk becomes excessive, it becomes more convenient to take the pluriactivity option, and employment in off-farm occupations implies less labor available for crop cultivation. This is coherent with the strategy to hedge against risk.

\section{Endnotes}

${ }^{1}$ Peter Bernstein (1996) suggests that "risk" derived from the early Italian word "risicare," meaning "to dare." In our context, the risk perception implies choices about crop 
combination (portfolio) to hedge the risk and is action-oriented. Markowitz (1952) was one of the first to apply the risk to the stock market portfolio.

${ }^{2}$ Expected utility theory, prospect theory, and most other models of risky choice are based on the fundamental premise that individuals choose among risky prospects by balancing the value of the possible consequences. These models therefore require that the value of a risky prospect lies between the value of that prospect's highest and lowest outcome. (Gneezy et al., 2006).

${ }^{3}$ Arrow (1970) said, "from the time of Bernoulli on, it has been common to argue that (a) individuals tend to display aversion to the taking of risks, and (b) the risk aversion in turn is an explanation for many observed phenomena in the economic world. Using Jensen's inequality, it can readily be shown that a necessary and sufficient condition for risk aversion is that the expected utility function is concave, i.e., $\mathrm{U}^{\prime \prime}(\mathrm{W})<0$ for all W."

${ }^{4} \mathrm{~A}$ study on farm income instability suggested that the variability of farm incomes in Italy increased during the period 2003-2008 and slightly declined in the next period 2008-12. The variability referred to type of farming also varied over time: for farms with highest productivity the variability of the sub-period 2008-2012 was generally higher than the period 2003-2007. (Severini et al. 2016). In this period, a growing number of farms closed.

${ }^{5}$ Enterprise diversification is a self-insuring strategy used by farmers to hedge against risk. Evidence exists that larger farms (higher income) are more specialized. Also, farmers who participate in off-farm work, farms located near urban areas, or with higher debt-to-asset ratios are less likely to be diversified. In contrast, evidence suggests there is a significant positive relationship between diversification and whether the farm business has crop insurance, is organized as a sole proprietorship, or receives any direct payments from current farm commodity programs.

${ }^{6} \mathrm{~A}$ lot of the literature on risk management in farming is on the subject of decision making (see Hardaker et al. 1988, 1991, 1997). Most frequent approaches are the E-V models, non-linear or quadratic or linearized versions such as MOTAD and target-MOTAD, others based on game theory such as maximin, minmax, and safety-first models. They frequently use covariance matrices to correlate the gross margins of individual crops with different states of nature and frequency to justify crop diversification as a strategy to hedge against risk. Non-iterative methodologies attempting to assess multi-criteria utility functions include at least one risky criterion, always requiring detailed information at farm level. A typical application is the combination of Bernoulli utility function and Bayesian analysis to elaborate an optimal portfolio with probabilities defined in two steps: (i) "ex ante" by using historical data; (ii) "ex post" adjustment with "ad hoc" experiments; these are merged to find the optimal solution by combining risky prospects with the ordered preferences.

${ }^{7}$ The diffuse cultivation of these crops in Italy make them potential candidates for the farm plan: they can be combined in rotation or used in repeated cultivations, or grown for optimal soil and climate adaptation. Some crops have alternative uses: maize can be used on the farm as cattle feed or biomass for renewable energy, sunflower seed oil can be sold to industry but its cake/meal is used as cattle feed; rapeseed (canola) and soybean are cultivated for seed oil production. All these crops are traded in cash markets and the long-term price trends suggest price coevolution. 
${ }^{8}$ Lien and Hardaker suggest that this length of time is appropriate to obtain reliable data for inference. It can be applied as an alternative to an elicitation procedure to determine subjective GI using the formula suggested by Hardaker.

${ }^{9}$ Risky prospects about farmer's gross incomes (GI) are given by yield and price fluctuations of the selected crops (Hazell 1971; Anderson and Hardaker 2003).GI is gross income less all expenses such as for seed, fertilizer, energy, property taxes, interest on debt, wages to hired labor, land rent, and machinery rent; this definition is equivalent to net revenue reported by Anderson et al. (1977).

${ }^{10}$ The GI of these crops, price variation, and co-integration among prices were discussed in other researches by Rosa et al. 2014; Rosa and Vasciaveo 2012a, 2012b.

${ }^{11}$ The literature suggests that "The change in frequency of extreme events that sometimes happened in the last years cannot be taken as scientific evidence of climate change that altered the probability distribution of climatic events." However, there is a lot of research work to incorporate the current information on changes in variability, as represented in climate models, into methods for assessing their probability distribution and implied risk in agriculture (Chen et al. 1999).

${ }^{12}$ These data were collected from Eurostat. Adding more, observations that change the value of mean and standard deviations were not relevant due to the random nature of events. According to some authors, the number of observations reported in the table is sufficient to estimate a reliable $\mathrm{E}-\mathrm{V}$ frontier with risky prospects.

${ }^{13}$ For pair variables composed by $n$ discrete time intervals, forming discrete distributions, the visual impact is the most direct method of observing the probability density function (PDF).

${ }^{14} \mathrm{CV}=$ S.D./M, a dimensionless number is a standardized measure of dispersion of a probability distribution or frequency distribution; it is independent of the unit in which the measurement was made and allows to compare mean values referred to variables with different scale of measurement. PDF is the probability density function, see Anderson et al. 1977).

\section{Acknowledgements}

Not applicable.

Funding

Not applicable.

Availability of data and materials

Not applicable.

Authors' contributions

All authors read and approved the final manuscript.

Competing interests

The authors declare that they have no competing interests.

\section{Publisher's Note}

Springer Nature remains neutral with regard to jurisdictional claims in published maps and institutional affiliations.

Received: 1 February 2018 Accepted: 4 April 2019

Published online: 02 May 2019

\section{References}

Anderson JR, Dillon JL, Hardaker JB (1977) Agricultural decision analysis. lowa State University Press, Ames.

Anderson JR, Hardaker JB (2003) Risk aversion in economic decision making: pragmatic guides for consistent choice by natural resource managers. In: Wessler J, Weikard HP, Weaver RD (eds) Risk and uncertainty in environment and natural resource economics. Edward Elgar, UK, pp 171-188. 
Anderson JR, Huirne RBM, Hardaker JB, Lien G (2004) Coping with risk in agriculture. CABI Publishing, Cambridge. Arrow KJ (1970) Essay in the theory of risk bearing. North Holland Publishing Company, Amsterdam.

Backus GBC, Eidman VR, Dijkhuizen AA (1997) Farm decision making under risk and uncertainty. Neth. J. Agric. Sci. 45:307-328. Bazerman MH, Moore DA (2006) Judgement in managerial decision making. 7th edt. John Wiley \& Sons, Inc.111 River Street, Hoboken, N.J

Bernstein P (1996) Against the gods: the remarkable story of risk. Wiley Teach, "Microsoft's Universe of Risk," CFO, 1997.

Brink L, McCarl BA (1978) The trade-off between expected return and risk among corn belt farmers. Am J Agric Econ 60:259263.

Chavas JP, Holt MT (1990) Acreage decisions under risk: the case of corn and soybean. Am J Agric Econ LXXII:529-538.

Chen CC, McCarl BA, Adams RM (1999) Economic implications of potential climate change induced ENSO frequency and strength shifts. Draft manuscript created as part of this report. Department of Agricultural Economics, Texas A\&M University and Oregon State University.

Dries L, Pascucci S, Gardebroek C (2012) Diversification in Italian farm systems: are farmers using interlinked strategies. New Medit 4:7-15.

Gneezy U, List JA, Wu G (2006) The Uncertainty Effect: When a Risky Prospect is Valued Less than its Worst Possible Outcome. The Quarterly Journal of Economics 121(4): 1283-1309.

Ghodake RD, Hardaker JB (1981) Whole-farm modeling for assessment of dryland technology. Economic program Progress report 29, international crops research Institute for the Semi-Arid Tropics ICRISAT Patancheru P.O. Andhra Pradesh 502 324, India.

Hanoch G, Levy H (1970) Efficient portfolio selection with quadratic and cubic utility. J Bus 43:181-190.

Hardaker JB, Huirne RBM, Anderson JR, Lien G (2007) Coping with risk in agriculture, 2nd edn. CABI Publishing, Wallingford.

Hardaker JB, Pandey S, Patten LH (1991) Farm planning under uncertainty: a review of alternative programming models. Rev Mark Agric Econ 59:9-22.

Hardaker JB, Patten LH, Pannell DJ (1988) Utility efficient programming for whole farm planning. Aust J Agric Econ 32:88-97.

Hazell P (1971) A linear alternative to quadratic and semivariance programming for farm planning under uncertainty. Am J Agric Econ 53:53-62.

Hazell P, Scandizzo PL (1974) Competitive demand structures under risk in agricultural linear programming models. Am J Agric Econ 56:235-244.

Hossain S, Hashim N, Mustapha N, Chen LT (2002) A quadratic application in farm planning under uncertainty. Int J Soc Econ 29:282-298.

Ignizio JP (1982) Linear programming in single and multiple objective systems. Prentice Hall Inc., Englewood Cliffs (NJ)

Kaine G, Lees J, Sandall J (1994) Planning and performance: an exploration of farm business strategy and perception of control. Rural Development Centre, University of New England, Armidale.

Kaiser HM, Apland J (1989) DSSP: a model of production and marketing decisions. On a midwestern crop farms. North Central J Agric Econ 11:157-170

Knight FH (1971) Risk, uncertainty, and profit. With an introduction by Stigler GJ., Phoenix Books. Chicago University Press.

Lambert DK, McCarl BA (1986) Risk modeling using direct solution of nonlinear approximation of the utility function. Am J Agric Econ 67:846-852.

Lee J, Brown DJ, Lovejoy S (1985) Stochastic efficiency versus mean variance criteria as predictor of adoption of reduced tillage. Am J Agric Econ 67:839-845.

Lien G, Hardaker JB (2001) Whole farm planning under uncertainty: impact of subsidy scheme and utility function on portfolio choice in Norwegian agriculture. Eur Rev Agric Econ 28:17-36.

Manfredo MR, Leuthold RM (1999) Value-at-risk analysis: a review and the potential for agricultural applications. Rev Agric Econ 21(1):99-111.

Markowitz H (1952) Portfolio selection. J Financ 7(1):77-91.

Martin S, Shadbolt NM (2000) Risk management strategies in the whole farming contest: the New Zealand experience. In: Income risk management in Agriculture, OECD Workshop, Paris.

Matlon PJ (1991) Farmer risk management strategies: the case of the West African semi-arid tropics. In: Holden D, Hazell P, Pritchard A (eds) Risk in agriculture. Proceedings of the Tenth Agriculture Sector Symposium. The World Bank 51-79.

McCarl BA, Önal H (1989) Linear approximation using MOTAD and separable programming: should it be done. Am J Agric Econ 71:158-166

Meuwissen MPM, Hardaker JB, Huirne RBM, Dijkhuizen AA (2001) Sharing risks in agriculture; principles and empirical results. Neth J Agric Sci 49:343-356.

Meyer J (1977) Second degree stochastic dominance with respect to a function. Int Econ Rev 18:477-487.

Mishra AK, El-Osta HS, Sandretto CL (2004) Factors affecting farm enterprise diversification. Agricultural Finance Review 64(2): $151-166$

Nakamura Y (1996) Sumex utility functions. Math Soc Sci 31(1):39-47.

OECD (2000) Income risk management in agriculture. Workshop, Paris,

OECD (2011) Managing risk in agriculture: Policy Assessment and Design. OECD Publishing, ISBN: 9789264116146 (PDF). Paris https://doi.org/10.1787/9789264116146-en.

Oguntade AE, Bamire AS (1994) Effect of risk attitudes on farm profitability among arable crop farmers: a case study. Indian J Agric Econ 38:531-542.

Pannell DJ, Nordblom TL (1988) Impacts of risk aversion on whole-farm management in Syria. Aust J Agric Resour Econ 42: 227-247.

Park SJ, Hwang CS, Vlek PLG (2004) Comparison of adaptive techniques to predict crop yield response under varying soil and land management conditions. Agric Syst 85:59-81.

Pope R (1982) Empirical estimation and use of risk preferences: an appraisal of estimation methods that use actual economic decisions. Am J Agric Econ 64:377-383.

Ray DE et al (1998) Estimating price variability in agriculture: implications for decision makers. J Agric Appl Econ 30:21-33.

Richardson JW, Klose SL, Gray AW (2000) An applied procedure for estimating and simulating multivariate empirical (MVE) probability distribution in farm level risk assessment and policy analysis. J Agric Appl Econ 32:299-315. 
Rosa F, Vasciaveo M (2012a) "Volatility in US and Italian agricultural markets, interactions and policy evaluation", in PRICE VOLATILITY AND FARM INCOME STABILISATION Modelling Outcomes and Assessing Market and Policy Based Responses, 123th EAAE Seminar, Dublin.

Rosa F, Vasciaveo M (2012b) The Relationship Between Oil and Agricultural Market" 28th International conference of Agricultural Economists, The Global Bioeconomy, Foz do Iguaçu, Brazil.

Rosa F, Vasciaveo M, Weaver R (2014) Agricultural and oil commodities: price transmission and market integration between US and Italy. BAE 3(2):93-117.

Salvioni C, Esposito L, Henke R, Rondinelli V (2009) Diversification strategies in small farms in Italy, 111 EAAE-IAAE seminar 'small farms: decline or persistence' University of Kent, Canterbury, UK 26th-27th June.

Severini S, Tantari A, Di Tommaso G (2016) Do CAP direct payments provide a disincentive to the development of the agricultural insurance market ? Paper presented at the 156th EAAE seminar: prospects for agricultural insurance in Europe. Wageningen (NL), 2-3 October

Shapiro JF, Wagner SN, Singhal VM (1993) Optimizing the Value Chain. Interfaces 23(2):102-117.

Stewart JI (1991) Managing climatic risk in agriculture. In: Holden D, Hazell P, Pritchard A (eds) Risk in Agriculture. Proceedings of the Tenth Agriculture Sector Symposium, The World Bank, pp 17-37.

Stovall JG (1966) Income variation and selection of enterprises. Am J Agric Econ 48(5):1575-1579.

Sulewski P. Kłoczko-Gajewska A (2014) Farmers' risk perception, risk aversion and strategies to cope with production risk: an empirical study from Poland. Stud Agric Econ 116(3):140-147

Taylor CR (1990) Two practical procedures for estimating multivariate non normal probability density function. Am J Agric Econ 72:210-217.

Tobin J (1965) The theory of portfolio selection. In: Hahn FH, Brechling FPR (eds) The theory of interest rates. Macmillan, New York.

Submit your manuscript to a SpringerOpen ${ }^{\circ}$ journal and benefit from:

- Convenient online submission

- Rigorous peer review

- Open access: articles freely available online

- High visibility within the field

- Retaining the copyright to your article

Submit your next manuscript at $>$ springeropen.com 